\title{
Pengukuran Performa Pitch-Roll dan Pitch-Yaw pada Sensor Inertia untuk Pengganti Mouse bagi Difabel
}

\author{
Rhesdyan Wicaksono Suherman, Romy Budhi Widodo, Reyna Marsya Quita
}

\begin{abstract}
Abstrak-Interaksi manusia dan komputer (Human Computer Interaction - HCI) adalah suatu ilmu yang mengkaji tentang interaksi antara manusia dengan komputer meliputi perancangan, evaluasi dan implementasi interface komputer agar mudah digunakan oleh manusia. Dengan dua kemajuan dibidang teknologi dan human computer interaction ini diharapkan dapat digunakan untuk membantu orang - orang yang memiliki keterbatasan yaitu penyandang disabilitas. Seseorang yang memiliki keterbatasan fisik seharusnya dibantu agar dapat tetap produktif meskipun dengan segala keterbatasan yang ada. Penelitian ini bertujuan membandingkan gesture pitch-roll dan pitch-yaw pada penggunaan sensor inersia untuk mengemulasikan gerakan kursor mouse yang dapat dimanfaatkan oleh penyandang disabilitas, dimana tidak dapat mengoperasikan mouse dalam kondisi normal. Setiap gesture akan dievaluasi menggunakan prosedur dalam ISO 9241-411 tentang evaluasi pointing device. Performansi kuantitatif yang diukur meliputi throughput dan movement time, sedangkan evaluasi kualitatif menggunakan angket uji kenyamanan. Hasil throughput untuk mouse sebesar 5.063 bps, untuk pitch-roll sebesar 1.114 bps sedangkan untuk pitch-yaw sebesar 1.116 bps. Hasil analisis statistik menyatakan terdapat perbedaan signifikan antara mouse dan kedua gesture sensor. Namun antar gesture tidak ditemukan perbedaan secara signifikan.
\end{abstract}

Kata Kunci-Difabel, Fitts' Law, Interaksi manusia dan komputer, ISO 9241-411.

\section{PENDAhUluan}

$\mathrm{I}$ nteraksi manusia dan komputer (Human Computer Interaction - HCI) adalah suatu ilmu yang mengkaji tentang interaksi antara manusia dengan komputer meliputi perancangan, evaluasi dan implementasi interface komputer agar mudah digunakan oleh manusia. Interaksi manusia dengan komputer merupakan serangkaian proses dan dialog yang dilakukan manusia untuk berinteraksi dengan saling memberikan input dan feedback melalui interface agar memperoleh output yang sesuai. Contoh interaksi dasar yaitu ketika kita menggunakan mouse yang telah didesain secara ergonomis sesuai dengan kenyamanan fisik tangan manusia untuk memberikan input kepada komputer agar melakukan perintah tertentu.

Masukan ke komputer dapat berwujud pointing device yang memerlukan evaluasi. ISO 9241-411 merupakan sebuah standard pengujian pointing device. Berbagai penelitian telah menggunakan standar tersebut seperti terdapat pada [1] yang membandingkan relatif dan absolute pointing device. Natapov, dkk [2] juga menggunakan standar ini untuk membandingkan Wii remote dan Wii classic controller. Sedangkan dalam [3] dibahas evaluasi performansi dari mouse, trackball, joystick, dan touch pad. Pointing device jenis laser pointer juga dibahas dan dievaluasi pada [4], [5]. Berdasarkan atas penelitian-penelitian terdahulu, ISO menjadi perhatian peneliti dalam memenuhi standar pengujian performansi.

Usaha-usaha menggantikan mouse telah dilakukan diantaranya penggunaan jenis sarung tangan mouse dengan sensor akselerasi dan fiberoptik [6], [7]; dan juga usaha penggunaan ultrasonik dan magnetic tracker [6], [8]. Namun belum ada pembahasan gesture yang digunakan dan evaluasinya.

Salah satu bagian tubuh yang dapat dimanfaatkan untuk meng-emulasi gerakan mouse pada keadaan tidak duduk adalah pergelangan tangan. Gerakan pergelangan tangan yang menyerupai orientasi pitch dan yaw dibahas dalam [9], demikian juga gerakan lengan bawah yang menyerupai orientasi roll dibahas dalam [10]. Gerakan anggota tubuh dalam tiga derajat kebebasan merupakan kandidat yang tepat untuk dipakai menggantikan gerakan kursor mouse.

Dengan kemajuan di bidang teknologi dan human computer interaction ini diharapkan dapat digunakan untuk membantu orang yang memiliki keterbatasan yaitu penyandang disabilitas. Komputer adalah salah satu media yang dapat digunakan untuk melakukan produktivitas sehari - hari. Salah satu alat untuk memberikan perintah untuk komputer adalah menggunakan mouse. Bagi mereka yang tidak dapat duduk akibat sakit atau lainnya, sehingga harus berada di tempat tidur, tentunya akan kesulitan apabila harus menggunakan mouse optik biasa.

Oleh karena itu melalui penelitian ini akan dilakukan riset untuk membandingkan antara mouse konvensional dan penggunaan sensor inertia dengan gesture pitch-roll dan pitch-yaw sebagai pengganti gerakan kursor mouse.

\section{MEtode PENELITIAN}

\section{A. Inertial Sensor}

Sensor inertial adalah sensor yang menggabungkan tiga buah sensor, yaitu accelerometer, gyroscope dan magnetometer. Sensor ini dapat mengeliminasi kelemahan-kelemahan tiap-tiap sensor dengan menggabungkannya. Alat ini dapat memperkirakan posisi relatif, kecepatan dan akselerasi dari sebuah gerakan.

Sensor ini bekerja dengan mempertahankan 6-degree- 
of-freedom (DOF) yang memperkirakan gerakan posisi (X Y Z) serta orientasinya (roll, pitch, yaw). Sistem ini bekerja secara terus menerus dengan melakukan perhitungan secara konstan dari orientasinya. Selain itu, sistem ini juga melakukan perhitungan untuk mempertahankan sikap motor 6-DOF dengan tetap melakukan perhitungan kecepatan dan akselerasi [11].

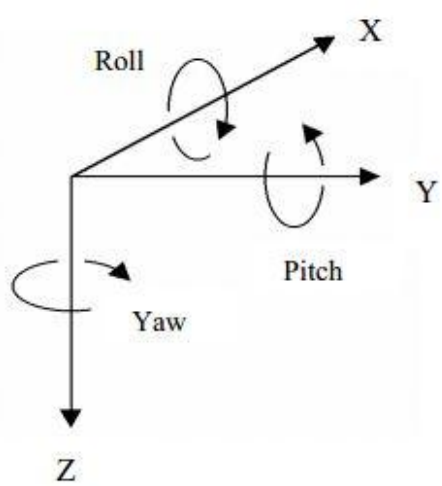

Gambar 1 Output perhitungan yang dihasilkan oleh inertial sensor [11]

\section{B. Implementasi ISO 9241-411 dan Fitts' Law}

Pada tes yang dilakukan, akan digunakan multidirectional tapping test dengan memperhatikan standar yang telah ditetapkan oleh ISO. Salah satu variabel ukuran ISO adalah Throughput (TP). TP ini diukur dengan satuan bits per second (bps) dan mencakup perhitungan kecepatan dan akurasi dari perangkat yang digunakan dalam satu dimensi. Throughput memanfaatkan perhitungan movement time $\left(\mathrm{t}_{\mathrm{m}}\right)$ dengan effective index of difficulty $\left(\mathrm{ID}_{\mathrm{e}}\right)$.

$$
\begin{aligned}
& T P=\frac{I D_{e}}{t_{m}} \\
& I D_{e}=\log _{2} \frac{d+w_{e}}{w_{e}} ; w_{e}=4.133 . s_{x}
\end{aligned}
$$

Movement time dihitung dari klik target satu ke target berikutnya. Movement time dihitung mulai klik pada target 1 hingga 25 dan diambil nilai rata-ratanya. $\mathrm{ID}_{\mathrm{e}}$ mengukur seberapa tingkat kesulitan efektif sesuai posisi klik oleh subyek saat pengujian dan satuan yang digunakan adalah bits. Sedangkan $d$ merupakan jarak pergerakan menuju target (pada Gambar 2, $d$ adalah diameter lingkaran besar) dan $w_{e}$ adalah effective target width yang dikaitkan dengan entropi, dimana berisi kumpulan koordinat yang dipilih dari subyek dalam pointing/tapping test.

Dalam pengambilan data, terdapat empat buah tingkat kesulitan. Dalam empat mode ini terdapat nilai $I_{D}$ yang berbeda - beda. Contoh perhitungannya untuk yang levels high dengan $d=800$ pixel dan $w=12$ pixel adalah sebagai berikut:

$$
\log _{2} \frac{800+12}{12}=6,06
$$

Secara detail perancangan index of difficulty pada penelitian ini diperlihatkan pada tabel 1 .

Pada penelitian ini ID very low disebut mode 1 , level low disebut mode 2, level medium disebut mode 3, dan level high disebut mode 4. Sedangkan pointing device yang diujicobakan adalah mouse, sensor dengan gesture

\begin{tabular}{|c|c|c|c|}
\hline $\begin{array}{c}\mathrm{d}^{\mathrm{a}} \\
\text { (pixel) }\end{array}$ & $\begin{array}{c}\mathrm{w}^{\mathrm{b}} \\
\text { (pixel) }\end{array}$ & $\begin{array}{l}\mathrm{I}_{\mathrm{D}}{ }^{\mathrm{c}} \\
\text { (bits) }\end{array}$ & $\begin{array}{c}\text { Index of difficulty } \\
\text { levels }\end{array}$ \\
\hline 800 & 12 & 6.06 & High $\quad($ ID $>6)$ \\
\hline 600 & 20 & 4.95 & ${\underset{\leq 6)}{\text { Medium }}(4<\mathrm{ID}}$ \\
\hline 600 & 60 & 3.45 & Low $<4)^{(3<\mathrm{ID}}$ \\
\hline 350 & 50 & 3 & Very low $(\mathrm{ID} \leq 3)$ \\
\hline
\end{tabular}
pitch-roll, dan sensor dengan gesture pitch-yaw,
Tabel 1 Rancangan desain Index of Difficulty

sehingga disebut ada tiga piranti. Pada pengambilan data, setiap subyek melakukan trial sebanyak 3 kali pada setiap mode dalam satu blok, sedangkan untuk setiap piranti akan diuji sebanyak 3 blok. Perhitungan total jumlah pengulangan tes yang dilakukan setiap subyek sebanyak 3 piranti, 4 mode, 3 blok, dan 3 trial per blok; sehingga keseluruhan berjumlah 108 tes per subyek Dalam melakukan tes, untuk mengurangi learning effects dari subyek, maka dalam pemilihan mode akan dilakukan secara acak tiap bloknya. Perancangan pengambilan data akan mengikuti standar ISO untuk multidirectional-tapping test seperti juga digunakan pada [12], [13].

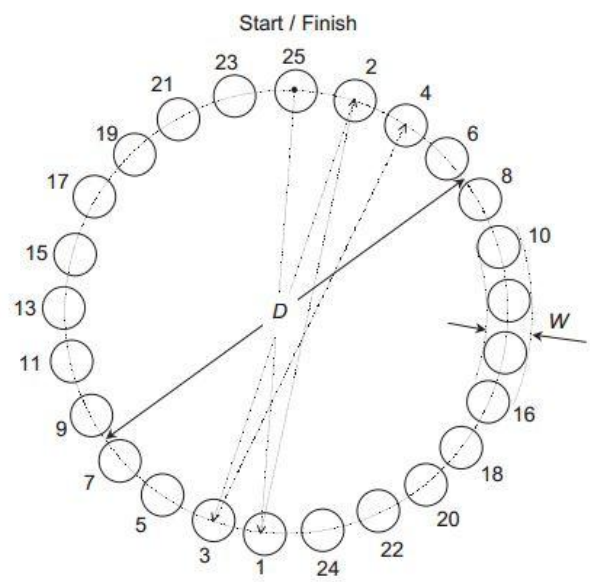

Gambar 2 Contoh rancangan multidirectional tapping test [13]

Dari rancangan tersebut, subyek akan mengklik target sesuai dengan urutan angka yang tertera pada Gambar 2.

Setelah menyelesaikan tes maka subyek mengisi angket untuk uji kenyamanan (comfortability) dan kelelahan (fatigueness) setiap piranti dengan tujuan untuk mendapatkan data kualitatif. Skala yang digunakan dalam angket adalah Likert 0 sampai dengan 7. Nilai 7 merupakan nilai tertinggi untuk kenyamanan dan terendah untuk kelelahan; sedangkan nilai 1 merupakan nilai terendah untuk kenyamanan dan tertinggi untuk kelelahan. Angket kedua adalah angket yang mengukur usaha (effort) yang digunakan untuk tiap piranti pada lengan, bahu, dan leher dengan skala maksimal 10 (Borg scale). Nilai 10 menyatakan dibutuhkan usaha yang paling besar, sedangkan nilai 0 menyatakan tidak ada usaha sama sekali untuk menggerakkan piranti yang sedang diuji. 


\section{Prosedur}

Dua belas subyek dengan rata-rata umur 25 tahun diambil dari mahasiswa dan alumni. Semua subyek melakukan pengambilan data secara individual dengan jarak $50 \mathrm{~cm}$ dari monitor. Pengambilan data dan perekaman dengan software mencakup: koordinat klik pada target, jumlah error, dan perekaman waktu $\left(t_{m}\right)$. Sedangkan $T P$ dihitung secara offline saat analisis data. Sensor dipasang di punggung tangan menggunakan perban. Setiap mode akan diacak tiap bloknya. Dalam pengambilan data menggunakan sensor dilakukan kalibrasi sudut (levelling) terlebih dahulu untuk menyesuaikan dengan kenyamanan pengguna. Pada saat tes, subyek diminta untuk meng-klik target berwarna merah lalu secara bergantian target tersebut berganti sesuai urutan nomor pada Gambar 2 hingga 25 target selesai. Saat itu waktu juga dicatat dengan software C\#. Semua tes dilakukan dengan duduk di kursi dan diperbolehkan istirahat sebentar apabila telah menyelesaikan tes setiap bloknya. Namun pada hari yang sama diharusnya menyelesaikan tes minimal satu piranti. Setelah menyelesaikan satu piranti, subyek diminta mengisi kuesioner.

Proses pengambilan data dilakukan dengan komputer berspesifikasi sebagai berikut:

- $\quad$ Pentium® Dual-Core CPU $2.70 \mathrm{Ghz}$

- RAM $4 \mathrm{~Gb}$

- VGA Intel G41 Express

- Windows 8.1 Enterprise 32-bit (6.3, Build 9600)

- Keyboard Microsoft ${ }^{\circledR}$ Wired Keyboard 500

- Mouse Logitech M100

- Monitor LG Flatron L177WSB

- Resolusi Monitor 1440x900 (60Hz)

- Intersense Inertia Cube 4

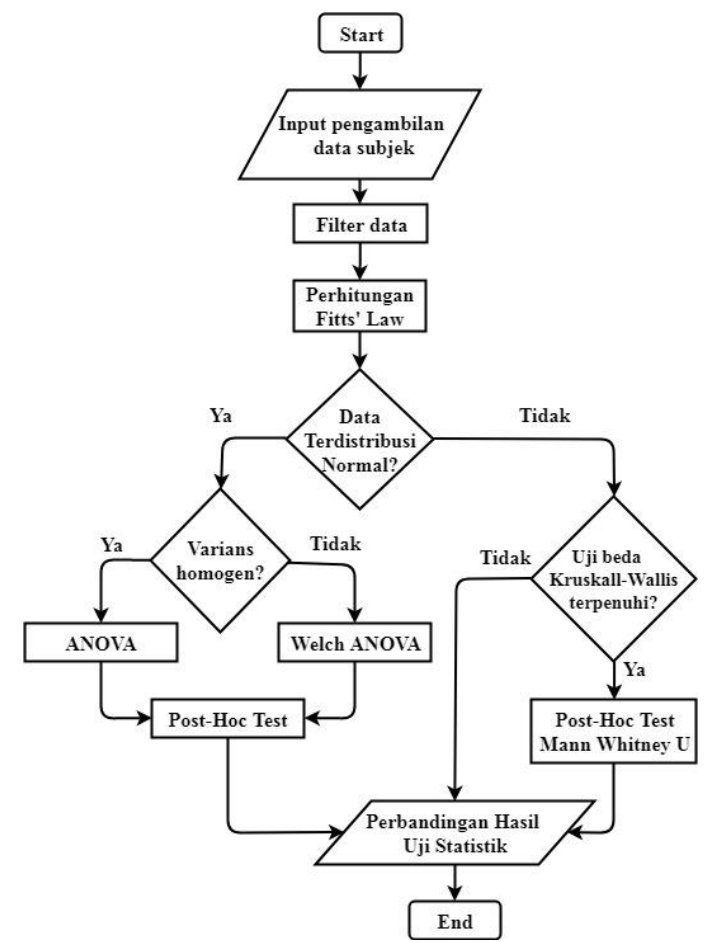

Gambar 3 Flowchart penelitian

\section{Diagram alir penelitian}

Untuk memudahkan penjelasan langkah - langkah dari penelitian ini akan digambarkan flowchart pada Gambar 3. Pada Gambar 3 dijelaskan urutan mulai dari pengambilan data kemudian melakukan proses perhitungan Fitts' Law hingga melakukan uji statistik dan dilakukan komparasi antar piranti untuk mengetahui tingkat signifikansi perbedaannya.

\section{HASIL DAN PEMBAHASAN}

\section{A. Pemrosesan Data Kuantitatif}

Setelah selesai pengumpulan data, dilakukan pemrosesan data dari hasil tes agar dapat siap untuk dianalisis dengan menggunakan statistik. Apabila setiap subyek melakukan 108 tes maka akan diperoleh data sebanyak 1.296 untuk 12 subyek. Lalu setelah itu dilakukan perhitungan Fitt's Law untuk mendapatkan nilai TP (throughput) dan $t_{m}$ (movement time). Hasil

Tabel 2 Hasil pengolahan data menggunakan Fitt's

\begin{tabular}{ccc}
\multicolumn{3}{c}{ Law } \\
\hline Type & $\begin{array}{c}\text { TP mean } \\
\text { (bps) }\end{array}$ & $\begin{array}{c}\mathrm{t}_{\mathrm{m}} \text { mean } \\
\text { (detik) }\end{array}$ \\
\hline Mouse & 5.063 & 0.8749 \\
Pitch-Roll & 1.114 & 3.0644 \\
Pitch-Yaw & 1.116 & 2.9245 \\
\hline
\end{tabular}

pengolahan data dijabarkan pada tabel 2 .

Dari hasil perhitungan Fitts' law diatas akan dilakukan uji statistik untuk mengetahui apakah ada perbedaan yang signifikan secara statistik. Analisis untuk data kuantitatif akan dibagi dari sisi $T P$ dan $t_{m}$. Pengujian statistik diolah menggunakan software IBM SPSS Statistic 20.

Yang pertama untuk pengujian TP akan dilakukan uji normalitas untuk mengetahui apakah data terdistribusi dengan normal. Sebaran data dari $T P$ ditampilkan di

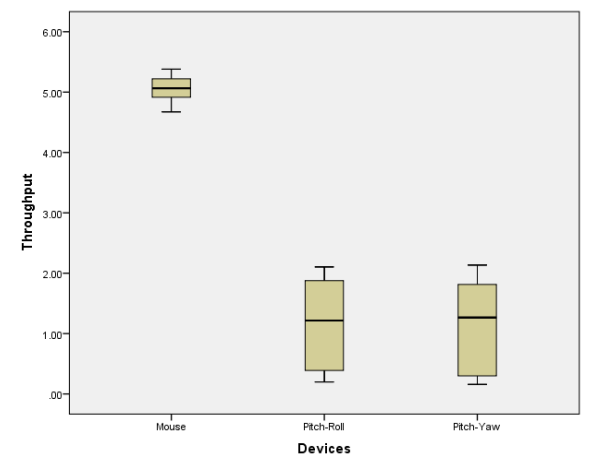

Gambar 4 Boxplot dari data TP

Gambar 4.

Dari Gambar 4 dapat dilihat persebaran dari kuartil pertama $\left(\mathrm{Q}_{1}\right)$ yang memotong $25 \%$ dari data terendah lalu median $\left(\mathrm{Q}_{2}\right)$ atau nilai tengah dan kuartil tertinggi $\left(\mathrm{Q}_{3}\right)$ yang memotong $25 \%$ dari data tertinggi. Setelah itu akan dilakukan uji normalitas dengan menggunakan Shapiro-Wilk. Hasil dari Shapiro-Wilk Test adalah data dari TP tidak terdistribusi normal karena nilai signifikan dari pitch-yaw kurang dari 0.05. Dari hasil tersebut akan dilakukan non-parametric test yaitu Kruskall-Wallis agar dapat diketahui terdapat perbedaan yang signifikan 
antar devices. Hasilnya nilai signifikan dari KruskallWallis kurang dari 0.05 yang berarti terdapat perbedaan signifikan. Namun untuk mengetahui dimana letak perbedaan signifikan harus dilakukan post-hoc test menggunakan Mann-Whitney U Test. Tes ini akan dilakukan 3 kali untuk membandingkan antar satu dengan lainnya.

Dari hasil Mann-Whitney U Test dapat diambil kesimpulan bahwa pada pitch-roll dan pitch-yaw tidak terdapat perbedaan secara signifikan karena nilai $p$ yang sebesar 0.862 dan tidak memenuhi syarat untuk berbeda secara signifikan karena lebih besar dari 0.05 sedangkan perbedaan signifikan hanya terdapat pada mouse dengan kedua sensor karena nilai $p$ kurang dari 0.05 .

Setelah menguji $T P$, langkan selanjutnya adalah menguji $\mathrm{t}_{\mathrm{m}}$. Gambar 5 menunjukkan boxplot dari data

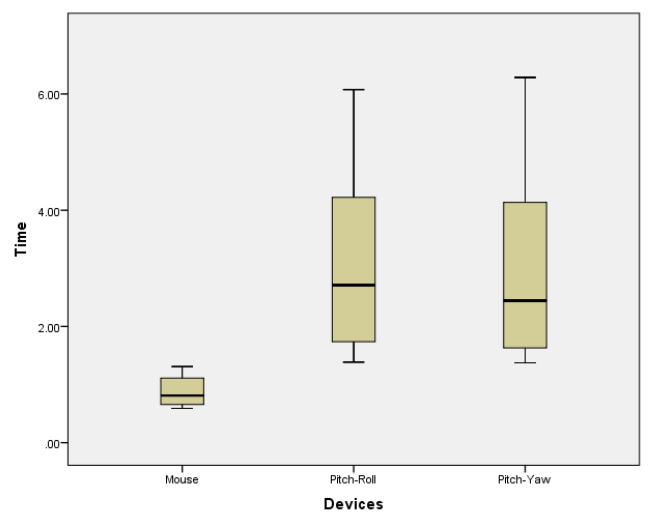

Gambar 5 Boxplot dari data $\mathrm{t}_{\mathrm{m}}$

$\mathrm{t}_{\mathrm{m}}$

Setelah itu akan dilakukan uji normalitas dengan menggunakan Shapiro-Wilk. Hasil dari Shapiro-Wilk Test adalah data dari $\mathrm{t}_{\mathrm{m}}$ terdistribusi normal karena nilai signifikan lebih dari 0.05. Dari hasil tersebut akan dilakukan tes homogenitas varian dengan menggunakan Levene Test untuk mengetahui tingkat homogenitas varian. Hasilnya nilai signifikan dari Levene Test kurang dari 0.05 yang berarti terdapat perbedaan signifikan. yang berarti varian dari tiap kategori tidak sama sehingga nilai variannya berbeda. Karena hasil dari Levene Test dinyatakan tidak lolos maka tes selanjutnya untuk mengetahui apakah terdapat perbedaaan secara signifikan $t_{m}$ antar devices adalah uji dengan menggunakan Welch ANOVA. Hasil dari Welch ANOVA dapat diketahui terdapat perbedaan signifikan karena nilai p kurang dari 0.05. Namun untuk mengetahui perbedaan itu terdapat pada devices mana diperlukan post-hoc test untuk membacanya. Post-hoc test yang digunakan yaitu Games-Howell Post-Hoc Test. Dari hasil post-hoc test dapat disimpulkan bahwa perbedaan signifikan untuk $t_{m}$ hanya ada pada mouse dengan sensor karena nilai $p$ kurang dari 0.05 sedangkan pada pitch-roll dengan pitch-yaw nilainya diatas 0.05 sehingga tidak terdapat perbedaan signifikan.

\section{B. Pemrosesan Data Kualitatif}

Dari setiap subyek akan diambil rata-rata untuk mengetahui tingkat comfortability dan fatigue dari tiap devices. Hasil dari rata-rata assessment of comfortability and fatigue dapat dilihat pada Tabel 3. Untuk comfort dan fatigue digunakan skala maksimal 7 untuk paling nyaman, sedangkan untuk effort digunakan skala

\begin{tabular}{lrrr}
\multicolumn{4}{c}{ Tabel 3. Hasil dari assessment of effort \& fatigue } \\
\hline Type & $\begin{array}{c}\text { Comfort } \\
\text { (mean) }\end{array}$ & $\begin{array}{r}\text { Fatigue } \\
\text { (mean) }\end{array}$ & $\begin{array}{c}\text { Effort } \\
\text { (mean) }\end{array}$ \\
\hline Mouse & 6.58 & 6.33 & 1.06 \\
Pitch-Roll & 3.48 & 3.93 & 4.94 \\
Pitch-Yaw & 4.02 & 4.70 & 3.39 \\
\hline
\end{tabular}

maksimal 10 (Borg scale) untuk menyatakan dibutuhkan usaha yang besar.

Dapat disimpulkan dari hasil diatas bahwa mouse sebagai perangkat konvensional tentu memiliki tingkat comfortability urutan pertama. Urutan kedua oleh pitchyaw dengan nilai rata - rata 4.02 dan urutan ketiga yaitu pitch-roll yang memiliki tingkat comfortability dengan nilai rata - rata dibawah 3.5. Hal yang sama berlaku pada fatigue test dimana mouse terbukti tidak membebani subyek dan diikuti pitch-yaw kemudian pitch-roll.

Berikutnya merupakan assessment of effort untuk mengukur seberapa besar effort yang dilakukan untuk menggunakan tiap piranti. Untuk pengolahannya, sama seperti comfortability and fatigue test yaitu rata-rata untuk setiap subyek. Dari hasil di Tabel 3, dapat disimpulkan melalui Borg scale bahwa mouse memiliki effort paling terendah pengoperasiannya. Nilai 1.06 mengacu pada kategori very weak effort sedangkan untuk pitch-yaw dengan nilai 3.39 dapat dikategorikan moderate effort dan yang terakhir pitch-roll dikategorikan strong effort (4.94).

\section{KESIMPULAN}

Penelitian ini menghasilkan beberapa simpulan sebagai berikut:

1. Penelitian ini menunjukkan bahwa orientasi pitchyaw dan pitch-roll dapat digunakan untuk mengemulasi gerakan kursor mouse. Dan memberikan kontribusi tentang perbandingan kedua gesture tersebut.

2. Perhitungan rata - rata TP (Throughput) dan $t_{m}$ (movement time) untuk mouse adalah 5.063 bps dan 0.874 detik lalu untuk pitch-roll 1.114 bps dan 3.064 s sedangkan untuk pitch-yaw 1.116 bps dan 2.924 detik. Dari perhitungan tersebut secara statistik dapat disimpulkan bahwa terdapat perbedaan signifikan antara mouse dengan pitchroll maupun pitch-yaw.

3. Tidak ditemukan perbedaan signifikan secara statistik pada perhitungan TP (Throughput) dan $t_{m}$ (movement time) antara pitch-roll dengan pitchyaw meskipun hasil performansi pitch-yaw diatas pitch-roll.

4. Untuk tingkat comfortability dan fatigue, mouse sebagai perangkat konvensional memiliki tingkat kenyamanan paling tinggi dan tidak membebani pengguna, mouse memiliki rata-rata nilai 6.58 (comfort) dan 6.33 (fatigue), sedangkan untuk pitch-yaw diurutan kedua dengan nilai 4.02 (comfort) dan 4.70 (fatigue) sedangkan pitch-roll 
diurutan ketiga dengan nilai 3.48 (comfort) dan 3.98 (fatigue).

5. Untuk tingkat effort yang dibutuhkan dalam pengoperasian, mouse tetap menjadi alat yang paling efektif dengan sedikit effort dengan nilai 1.06 (very weak effort) yang dibutuhkan dan pitchyaw terbukti lebih memerlukan effort dengan nilai 3.39 (moderate effort) jika dibandingkan dengan mouse sedangkan pitch-roll diperlukan effort paling tinggi dengan nilai 4.94 (strong effort).

\section{SARAN}

Untuk pengembangan penelitian selanjutnya dapat dilakukan pengembangan prototipe untuk mewujudkan mouse bagi difabel; dengan memanfaatkan gesture pitch-yaw maupun pitch-roll.

\section{DAFTAR PUSTAKA}

[1] K. L. Norman and K. D. Norman, "Comparison of Relative Versus Absolute Pointing Devices," HumanComputer Interact. Lab, pp. 1-17, 2010.

[2] D. Natapov, S. J. Castellucci, and I. S. MacKenzie, "ISO 9241-9 Evaluation of Video Game Controllers," Proc. Graph. Interface Conf., pp. 223-230, 2009.

[3] I. S. MacKenzie, T. Kauppinen, and M. Silfverberg, "Accuracy measures for evaluating computer pointing devices," Proc. SIGCHI Conf. Hum. factors Comput. Syst. - CHI '01, pp. 9-16, 2001.

[4] J.-Y. Oh and W. Stuerzlinger, "Laser Pointers as Collaborative Pointing Devices," Proc. Graph. Interface Conf., pp. 141-149, 2002.

[5] R. B. Widodo and T. Matsumaru, "Measuring the performance of laser spot clicking techniques," in 2013 IEEE International Conference on Robotics and Biomimetics, ROBIO 2013, 2013.

[6] T. G. Zimmerman, J. Lanier, C. Blanchard, S. Bryson, and Y. Harvill, "A hand gesture interface device," ACM SIGCHI Bull., vol. 17, no. SI, pp. 189-192, 1986.

[7] K. S. J. Perng, J.K.; Fisher, B.; Hollar, S.; Pister, "Acceleration sensing glove (ASG)," in Wearable Computers, 2002, pp. 178180.

[8] J. Z. Zimmerman, Thomas G.; Lanier, "Computer data entry and manipulation apparatus and method," 1989.

[9] D. H. Gates, L. S. Walters, J. Cowley, J. M. Wilken, and L. Resnik, "Range of motion requirements for upper-limb activities of daily living," Am. J. Occup. Ther., vol. 70, no. 1, 2016.

[10] Nelson D.L.; Mitchell M.A.; Groszewski P.G.; Pennick S.L.; Manske P.R., "Wrist Range of Motion in Activities of Daily Living," in Advances in the Biomechanics of the Hand and Wrist. NATO ASI Series (Series A: Life Sciences), Schuind F.; An K.N.; Cooney W.P.; Garcia-Elias M., Ed. Springer, Boston, MA, 1994, p. vol. 256

[11] D. B. Setiawan, Joga Dharma; Widodo, Achmad; Nugroho, "Perancangan dan Pembuatan Platform Validasi Inertial Measurement Unit (IMU)," Rotasi, vol. 13, no. 1, pp. 1-7, 2011.

[12] I. S. Mackenzie, "Fitts' Law," in Handbook of human-computer interaction, vol. 1, Wiley, 2018, pp. 349-370.

[13] R. W. Soukoreff and I. S. MacKenzie, "Towards a standard for pointing device evaluation, perspectives on 27 years of Fitts' law research in HCI," Int. J. Hum. Comput. Stud., vol. 61, no. 6, pp. 751-789, 2004. 